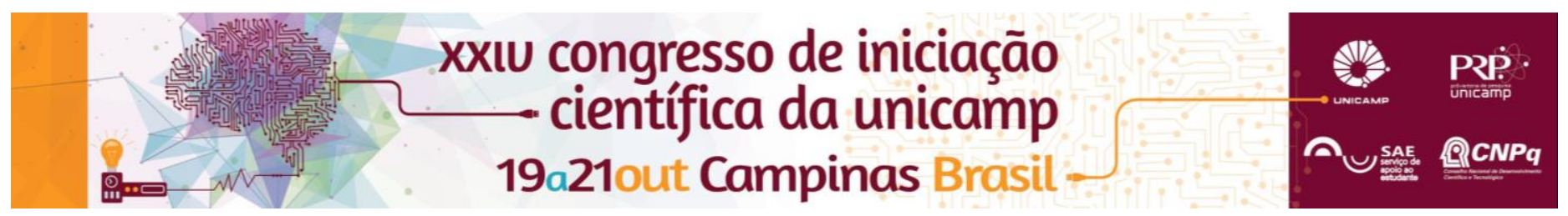

\title{
Análise dos esforços em transgenia e melhoramento de cultivares de Eucalipto no Brasil.
}

\author{
Bruna Estefânia Pires*, José Maria Ferreira Jardim da Silveira.
}

\section{Resumo}

O projeto analisou a dinâmica da produção de conhecimento no setor florestal brasileiro, focando em biotecnologia aplicada a cultura de Eucalipto, esfera que sofreu profundas mudanças estruturais, como a grande internacionalização, o desenvolvimento de novos modelos institucionais de parcerias público-privada e os investimentos na formação de $\begin{array}{llllll}\text { Redes de } & \text { Pesquisa } & \text { Genômica } & \text { Florestal. }\end{array}$

\section{Palavras-chave}

Eucalyptus, Biotecnologia, Indústria de base florestal.

\section{Introdução}

Em 2013, cultivares de Eucalyptus ocupavam $72 \%$ da área de floresta plantada no Brasil, valor que o posiciona como a quarta cultura em área cultivada no Brasil, sendo a indústria de papel e celulose o principal destino da produção. Cacterística marcante desta cultura, a alta produtividade brasileira de árvores de Eucalyptus fortalece a competitividade da indústria nacional ${ }^{1}$, sendo 0 melhoramento genético, foco deste projeto, o principal responsável por ela.

Um dos aspectos evidentes ${ }^{2}$ do modelo atual de progresso tecnológico agrícola trata-se da maior complexidade da base de conhecimento aplicada às etapas produtivas da agricultura. Este trabalho buscou caracterizar as inovações que derterminaram o novo modelo.

\section{Resultados e Discussão}

Desde os anos 2000, houve uma tendência a maiores investimentos em P\&D de Eucalyptus no Brasil. Como resultado, além do aumento da produtividade média anual, o novo modelo organizacional do P\&D possibilitou o pioneirismo do Brasil na aprovação comercial de Eucalyptus GM.

Tabela 1. Estrutura do P\&D em Eucalyptus no Brasil

\begin{tabular}{|c|c|c|}
\hline Organização (2012) & $\begin{array}{l}\text { Breeding/Biotech } \\
\text { Investments }\end{array}$ & Executores \\
\hline Governo Federal & US\$ 32.5 milhões & Embrapa, Universidades \\
\hline $\begin{array}{l}\text { Fundações de pesquisa Estaduais } \\
\text { *(FAPESP 1996-2006) }\end{array}$ & US\$ 15 milhões & Universidades, Firmas \\
\hline Firmas Privadas - Ibá & US\$ 15 milhões & Indústria, Universidade \\
\hline $\begin{array}{l}\text { Firmas Privadas - Multinacionais } \\
\text { de biotecnologia florestal }\end{array}$ & US\$ 4.6 milhões & Indústria, Universidade \\
\hline
\end{tabular}

Fonte: Baseado em King, Fuglie and Toole (2012), Dados da Pesquisa

No que diz respeito ao novo modelo de gerenciamento da propriedade intelectual, os resultados apontam que as redes de pesquisa já concluídas apresentaram como principal inovação o envolvimento de um maior número de organizações de pesquisa e uma mudança no papel do setor público, que se torna o principal ator na definição da agenda pesquisada. A mudança no estilo de gerenciamento do conhecimento determinou o novo tratamento que as tecnologias criadas recebem, são agora inovações abertas, sendo divulgadas em base de dados.
Figura 1. Novo Modelo Institucional de Parceira Público Privado em P\&D Florestal

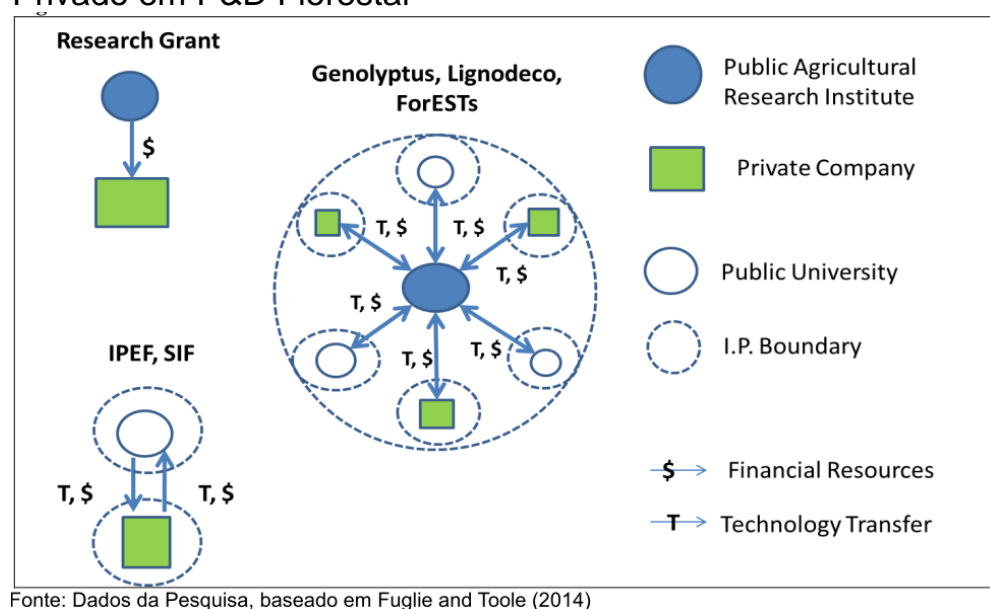

\section{Conclusões}

O desenvolvimento de novos modelos institucionais de parceria público-privado alterou a divisão de trabalho entre público-privado, mas não aumentou a habilidade de instituições públicas em comercializar os resultados das pesquisas, papel executado pelas instituições privadas. Coube ao setor público assumir os mecanismos de financiamento para incentivo de parcerias.

Entretanto, apesar de todo investimento e do novo modelo institucional apontados até agora, o setor de P\&D florestal brasileiro ainda apresenta uma grande concentração nos Estados mais ricos do país, mesmo em regiões onde não existe formação especializada no setor. Fato que pode enfrquecer a sustentabilidade da expansão das florestas plantadas, que pode sofrer com uma grande escassez de capital humano.

\section{Agradecimentos}

Agradeço ao CNPq, ao Instituto de Economia e ao Núcleo de Economia Agrícola e Ambiental pela oportunidade de realizar esta pesquisa.

\footnotetext{
1 BNDES. A indústria de papel e celulose, Editora BNDES- Rio de Janeiro. 2012.

2 Pardey, P.; Alston, J.; Chan Kang, C. Agricultural production, productivity and R\&D over the past half century: An emerging new world order. International Association of Agricultural Economists, mimeo, 2012.
} 